İş ve İnsan Dergisi | The Journal of Human and Work

Y1l | Year: Ekim | October 2019

Cilt-Sayı | Volume-Issue: 6 (2)

ss I pp: $199-208$

doi: $10.18394 /$ iid. 552555

e-ISSN 2148-967X

http://dergipark.gov.tr/iid/

Derleme Makalesi

\title{
Örgütlerde Yeşil İnsan Kaynakları Yönetimi Uygulamaları: Teorik Bir İnceleme
}

\author{
Green Human Resources Management in Organizations:
}

A Theoretical Approach

Ayla Zehra Oncer ${ }^{\mathrm{a}}$

\section{MAKALE BİLGİSI}

Anahtar Kelimeler:

Yeşil İnsan Kaynakları

Yönetimi, Yeşil Yönetim,

Yeşil Süreçler

Tarihler:

Geliş 11 Nisan 2019

Düzeltme geliş 26 Haziran

2019

Kabul 26 Temmuz 2019

\section{ÖZ}

Küresel rekabetin yarattı̆̆ baskı ve tüketicilerin giderek artan çevre bilinci işletmelerin yeşil yönetim felsefesini benimsemeleri konusunda itici güçler olarak karşımıza çıkmaktadır. Yeşil yönetim anlaylşını hayata geçirmenin başlıca yolu da iş̧letme fonksiyonlarında yeşil uygulamaların gerçekleştirilmesinden geçer. Bu noktada karşımıza çıkan en önemli fonksiyonel uygulamalardan biri yeșil insan kaynaklarl yönetimidir. İsletmede yeșil anlaylșının yerleșmesini sağlayacak ve sürdürecek olan çalışanların, işe alımdan itibaren tüm insan kaynakları fonksiyonlarında yeșil uygulamalarla karșllașmaları, yeșil ișletme olma ve yeșil yönetimi gerçekleştirme konusunda büyük destek sağlayacaktır. Söz konusu anlaylştan hareketle bu çalıșmanın amacl; öncelikle yeșil insan kaynakları yönetiminin ne olduğunu ele alarak önemini vurgulamak, bu sistem içerisinde yer alan işe alım, performans yönetimi, eğitim ve geliştirme, ücretlendirme, çalışan ilişsileri ve iş-yaşam dengesi süreçlerinin nasıl ele alınması gerektiği teorik olarak incelemektir. Bu sayede işletme yöneticilerini, insan kaynaklart süreçlerine bu anlayıșl nasıl adapte edebilecekleri konusunda bilgilendirebilmek ve söz konusu alanda yeterli çalışma olmadığından oldukça kısıtlı olan Türkçe literatüre katkıda bulunabilmektir. Yerli yazında yer alan çalıșmaların büyük kısmı çevresel sürdürülebilirlik konusuna ağırlı vermektedir. Bu çalışma ile insan kaynakları yönetimi fonksiyonlarında yeşil uygulamaların ne şekilde gerçekleştirilebileceği detaylı olarak ortaya konulmuştur.

\section{ARTICLE INFO}

\section{Keywords:}

Green Human Resources

Management, Green

Management, Green

Processes

Article history:

Received 11 April 2019

Received in revised form 26

June 2019

Accepted 26 July 2019

\begin{abstract}
A B S T R A C T
The pressure of global competition and the increasing environmental awareness of consumers are the driving forces for enterprises to adopt the green management philosophy. The main way to implement the green management approach is through the realization of green applications in business functions. One of the most important functional applications we face here is green human resources management. Experiencing green applications in all human resources functions starting from recruitment by the employees who will ensure and maintain the green understanding in the enterprise, will provide great support for becoming a green business and realizing green management. In the light of this understanding, the main purpose of this study is to emphasize the significance of green human resources management and explain both the concept and its functions such as, recruitment, performance management, training and development, compensation, employee relations and work-life balance. By this means, to inform business managers about how to adapt this understanding to human resources processes and to contribute to Turkish literature which is very limited since there is not enough study in this field. Most of the studies focus on environmental sustainability. In this study, how green practices can be realized in human resource management functions is explained in detail.
\end{abstract}

Illetişim kurulacak yazar Doç. Dr., Marmara Üniversitesi, İşletme Fakültesi, İşletme bölümü, Isstanbul, Türkiye. E-mail: oncer@marmara.edu.tr.ORCID: 0000-0002-6741-2718 


\section{GíRiş̧}

Günümüz işletmeleri, yalnızca uyumluluğu amaçlayan çevresel düzenleyeme yönelik reaktif bir yaklaşımın artık rekabetçi bir seçenek olmadığını ve çevre yönetiminde proaktif bir yaklaşım benimsenmesi gerektiğini kabul etmektedir. Proaktif çevre yönetimi uygulamalarını mümkün kılan üç organizasyonel kabiliyet; paylaşılan vizyon, paydaş yönetimi ve stratejik proaktif yönetimdir. Bu süreçlerde insan kaynaklarının etkisi büyüktür. Yeşil İnsan Kaynakları Yönetimi (İKY) uygulamaları hem proaktif çevre yönetimi hem de firma performansı üzerine önemli katkılarda bulunur (O’Donohue \& Torugsa, 2016).

İnsan kaynakları alanıyla ilgili sürdürülebilirlik çalışmaları son on yılda başlamıştır. Bu çalışmalara göre çevresel çalışmalarda insan kaynaklarının önemli rol oynadığı görülmüştür (Clark, 2013). Sürdürülebilirlik üzerine yapılan birçok araştırma, insan kaynakları yönetiminin bir organizasyona sürdürülebilirlik kültürünü getirmesinde önemli bir rol oynadığını ortaya koymaktadır. Sürdürülebilir iş modelleri ve iş uygulamaları şirketleri gelişmekte olan küresel ekonomide daha rekabetçi yapabilir. İKY uygulamalarındaki ortaya çıkan sürdürülebilirlik kavramı hem örgütsel hem de İKY işlevleri için önemli etkilere sahiptir. İnsan kaynakları yönetimi, işletme sürdürülebilirlik stratejilerinin geliştirilmesi ve uygulanmasını desteklemelidir. Çünkü insan kaynakları yönetiminin katkıları, işletme başarısı için kritik öneme sahiptir (Lakshmi \& Kennedy, 2017). Daha geniş bir perspektiften bakıldığında, çevresel sürdürülebilirlikte etkili ve başarılı olabilmek için İK'nın karar verme ve çevresel sürdürülebilirlik politikaları ve uygulamaları içinde daha fazla yer alması gerektiği savunulmaktadır (Harris \& Tregidga, 2012).

Günümüz işletmeleri kurumsal çevre yönetiminde, çevre bilincine ilişkin uluslararası düzenlemelere uymak için çevre koruma faaliyetlerini yürütmekten başka bir seçeneğe sahip değillerdir. Örgütleri çevresel konularla ilgilenmeye iten iki güç; Montreal Sözleşmesi ve Kyoto Protokolü gibi çevresel korumanın uluslararası güçleridir. Dünyada tüketicilerin de çevreciliği artmaktadır ve buna bağlı olarak bireylerin çevre dostu ürünleri seçme ve hatta yeşil ürünler için nispeten yüksek fiyat ödeme konusunda istekli olması işletmelerin kurumsal çevre yönetimi anlayışını benimsemelerini zorunlu kılmaktadır. Ayrıca çevre yönetimi için çaba harcayan işletmeler, yalnızca çevre koruma konusunda eleştirel sorunları ortadan kaldırmakla kalmaz, aynı zamanda kurumsal imajlarını iyileştirip, yeni pazarlar geliştirir ve rekabetçi avantajlarını da artırırlar.

Etkili bir yeşil yönetim sistemi uygulamak için örgütün tüm çalışanlarının teknik ve yönetsel becerilere sahip olması ve geliştirilmesi önemlidir. Etkili araçlar, sürdürülebilir çevresel faaliyetler firmalara önemli rekabet avantajı sağlar. $\mathrm{Bu}$ çerçevede etkin insan kaynağına sahip olmak için, çevre ve çevre bilincini içeren eğitimler, yetkilendirme programları ve ödül sistemleri de yeşil şirketlerin gelişimine katı sağlayacaktır (Cherian \& Jacob, 2012).

Güçlü yeşil politikalara sahip şirketlerin genel olarak artan satış, marka tanınırlığı ve arzu edilen çalışan sonuçları gibi alanlarda fayda sağladı̆̆ görülmektedir. İşletmeler artan bir şekilde, yeşil insan kaynakları uygulamalarını benimsemekte ve işyerlerinde çalışan davranışlarını teşvik etmektedir. İnsan Kaynaklarının çalışanların sürdürülebilirlikle ilgili davranışlarını, tutumlarını, bilgilerini ve motivasyonlarını artırma ve etkileme becerisine sahip olduğu ileri sürülmektedir (Clark, 2013). Bu nedenle, kuruluşlar, çevreye uyumlu sürdürülebilir politikaları etkili bir şekilde sunmak ve uygulamak için İnsan Kaynaklarını sürece dahil etmelidir. Örneğin, Yeşil İKY uygulamalarının çalışanların yeşil davranışlarını ortaya çıkarmada etkili bir güç olabilmesi için, firmanın benzer çevre değerlerine ve inançlarına sahip çalışanlarını istihdam etmesini amaçlayan işe alım stratejileri geliştirmesi, bireysel çevre performansı ve çevre bilincini destekleyen eğitim ve geliştirme programlarını uygulaması gerekmektedir. Yeşil İKY aşağıda özetlenen nedenlerden dolayı çalışanların davranışlarını etkiler. Birincisi, kuruluşun yeşil politikaları hakkındaki bilgileri yaygınlaştırmak, işe alımda bireysel değerleri vurgulamak ve eğitim yoluyla yeşil değerleri teşvik etmek gibi uygulamalar çalışanların yeşil bilincini artıracaktır. İkincisi, çevresel gereksinimleri karşılayan iş tasarımı ve çalışanların bilgi, beceri ve yetkinliği artırmak için tasarlanan yeşil eğitim uygulamaları, çevreci faaliyetler yürütmek için kilit süreçlerdir. Üçüncü olarak ise İKY süreçleri çalışanların neden bazı uygulamaları benimsediğini ve bunların çalışma davranışları üzerindeki etkinliğini belirlemektedir (Dumont, Shen \& Deng, 2017).

Yukarıda özetlendiği üzere işletmelerin sürdürülebilirlik çalışmalarının en önemli ayaklarından biri de Yeşil İKY uygulamalarıdır. Bu sebeple bu çalışmada insan kaynakları yönetimi fonksiyonları tek tek ele alınarak yeşil yönetim uygulamalarının her bir İK fonksiyonunda ne şekilde uygulanabileceği açıklanarak Türkçe yazına konuya ilişkin katkı sağlamaya çalışılmıştır. 


\section{YEŞİL İNSAN KAYNAKLARI YÖNETIMI KAVRAMI}

Çağdaş kuruluşlar için çevresel sürdürülebilirlik şarttır. Paylaşılan değerler yaratmak ve organizasyonel sürdürülebilirlik stratejilerini desteklemek için kapsamlı ve bütüncül bir insan kaynakları yönetimine ihtiyaç duyulmaktadır (Dilchhert \& Ones, 2012). Yeşil İKY alanındaki araştırmalar disiplinler arasıdır ve stratejik yönetim, organizasyonel performans, performans yönetimi, örgüt kültürü, çalışanların katılımı, personel geliștirme ve eğitim alanlarındaki örgütsel temalardan yararlanmaktadır. Yeşillendirme stratejisinin konumlandırılması ve kurumsal strateji ile organizasyon performansına uyum sağlaması, örgütlerde çevresel sürdürülebilirliğin geliştirilmesinde önemli bir unsurdur (Millar, Sanyal \& Camen, 2016).

Yeșil İKY, doğal kaynakların en verimli şekilde kullanılmasını sağlamak için insan kaynakları politika ve uygulamalarının kullanıldığı ve çevresel yönetimi teşvik eden bir alandır. Telekomünikasyon, kağıtların daha az kullanımı, iş paylaşımı, video konferans ve Skype yöntemi ile seyahatlerin azaltılması gibi mevcut kaynakların etkin kullanım yoluyla karbon ayak izlerini (üretilen sera gazı miktarı açısından insan faaliyetlerinin çevreye verdiği zararın ölçüsü) azaltmayı amaçlamaktadır. Dolayısıyla yeşil insan kaynakları; çevre dostu uygulamalar ve çalışanların bağlılı̆̆ sağlamak gibi temel unsurları barındırmaktadır (Ashraf, Ashraf \& Anam, 2015).

Yeşil İKY, finansal tabloların, sosyal ve ekolojik hedeflerin başarıyla tanımlanması ve aynı zamanda insan kaynakları tabanının yeniden yapılandırılmasını amaçlayan ve ortaya çıkan insan kaynakları stratejilerinin uygulanmasını amaçlayan bir yapı olarak ortaya çıkar. İşyeri dinamiklerindeki karmaşıklıkları ve İKY uygulamalarından kaynaklanan olumsuz etkileri önleme ihtiyacını açıkça belirterek, İKY için daha geniş amaçları belirleyerek, kişileri yönetmek için yeni bir yaklaşım sunmaktadır (Kramar, 2014).

Küreselleşme çok sayıda organizasyon için çevre sorunları yaratmıştır. $\mathrm{Bu}$ nedenle İK uygulamalarının daha yenilikçi ve çevre hedefleriyle uyumlu olması, İK profesyonellerinin yeşil uygulamaları benimsemesi yaşamsal önem taşır. Yeşil İKY, geleneksel İK uygulamalarının örgütün çevresel hedefleri ile sistemli, planlı bir şekilde yürütülmesi anlamına gelir (Jong \& Yusoff, 2016). Kaynakların sürdürülebilir kullanımını teşvik etmek ve örgütlerdeki çevresel kaygılardan kaynaklanan zararları önlemek için İK politikaları, felsefeleri ve uygulamalarının kullanılmasıdır (Mehta \& Chugan, 2015).

Organizasyonun çevresel hedeflerine ulaşmak ve çevresel sürdürülebilirliğe önemli katkılar sağlamak için çalışanları düşük karbon izli bir yaşam tarzına önem veren ve yeşil yönetim uygulamalarını destekleyen yeşil çalışanlar haline dönüştürmek İKY'nin temel hedefidir. Yeşil İKY, işletme çalışanlarını bireyin, toplumun, doğal çevrenin ve işin yararına yeşilleştiren politikalar, uygulamalar ve sistemleri ifade eder (Opatha \& Arulrajah, 2014). Yeşil İKY'ye yönelik işletmeler tarafından benimsenen bazı uygulamalar şunlardır; fiziksel depolama yerine elektronik ve dijital dosyalama alternatiflerini kullanmak ve gereksiz kağıt kullanımı önlemek, yakıt tasarrufu sağlamak ve trafikle zamandan tasarruf etmek için araç paylaşımına yönelmek, telekonferans ve online eğitimler gerçekleştirmek, mümkün olduğunca gün 1şığından faydalanmak, elektik kullanımında led ampullere yer vermek, doğal isitma, aydınlatmaya imkan veren yeşil binaların inşaatını desteklemek, sigara içilmeyen ofisler oluşturmak (sigara odası kullanım alanlarının olmaması vb.), sürdürülebilir yeşil fikirler için çalışanları ödüllendirmek, çalışanlara yeşillendirme ve atık yönetimi ile ilgili bilgilendirmeler yapmak vb. (Pandey, Viswanathan \& Kamboj, 2016).

Şirketler, yeşil uygulamaların sistemlerine başarılı bir şekilde entegre edilmesiyle önemli çevresel performansa erişebilirler. İnsan kaynaklarının kalitesi de bu uygulamaların yayılması için önemli bir faktördür. Nitelikli insan kaynaklarının varlığı süreçlerin daha kolay uygulanabilir hale gelmesini sağlayacaktır. Yeşil uygulamalar, disiplinler arası koordinasyon ve mevcut operasyon sürecinde önemli değişiklikler gerektiren karmaşık bir süreçtir. Dolayısıyla sürecin başarısı çalıșanların katılımını sağlayacak becerilerin geliştirilmesi ve eğitime bağlıdır (Ho, Lin \& Tsai, 2014).

Yeşil İKY'nin bir diğer boyutu da kurumsal sosyal sorumluluktur. Kisaca kurumsal sosyal sorumluluk; işletmelerin sosyal ve çevresel kaygılarını kendi ticari faaliyetleri ve paydaşlarıyla gönüllülük esasına dayalı olarak etkileșim içinde birleștirdikleri bir kavram olarak tanımlanabilir. Çevresel açıdan kurumsal sosyal sorumluluk faaliyetleri çevre dostu teknolojilerin kullanımı, geri dönüşüm ve kirliliğin azaltılması yoluyla yüksek düzeyde çevre performansının geliştirilmesini içerir (Raikkönen, 2011).

Tüm bu boyutlar değerlendirildiğinde Yeşil İKY'nin basit bir programdan daha fazlası olduğu gerçeği ortaya çıkar. İşletmenin vizyon ve stratejilerine dayanan ve sonuçta şirket kültürü 
haline gelen uzun vadeli, organizasyon çapında bir oluşumu gerektirir.

\section{YEŞIL İNSAN KAYNAKLARI YÖNETIMI UYGULAMALARI}

İnsan kaynakları alanındaki yetkinlikler, istihdam ve performans yönetimi gibi bireysel işlevlerden, örgütsel yap1 ve kültür tasarımı ve stratejik planlama gibi örgütsel işlevlere kadar uzanır. İnsan kaynaklarının bu yetkinliklere sahip olması, organizasyonun iş stratejilerini rekabetçi bir biçimde yürütmesini kolaylaştırmaktadır (Jong \& Yusoff, 2016). Teknoloji birçok alanda olduğu gibi insan kaynakları süreçlerinde de önemli bir etkiye sahiptir. Bununla birlikte insan kaynakları yöneticilerinin de rolü değişmiştir. Artık işletmelerin çoğu iş başvurularını online sistemler üzerinden almaktadır. Pozisyona uygun kriterlere göre adayları seçmek, online filtrelemeler sayesinde çok hızlı ve kolay bir yöntem haline gelmiştir. Çevrimiçi eğitimler ile çalışanların her ortamda bilgiye kolayca ulaşabilmesi, hız ve etkinlik anlamında da önemli bir yere sahiptir. Teknolojinin desteği ile ortaya çıkan bu ve benzeri uygulamalar Yeşil İKY alanının gelişmesini sağlamıştır. Yeşil İK sürecinde çalışanların uygulamalara katılımlarını sağlamak için insan kaynakları profesyonellerinin uygulayacağı çeşitli yollar bulunmaktadır: i) Yetenekli çalışanlar istihdam etmek, ii) Çalışanların katılımı ve gelişimi için uygulamalar tasarlamak, iii) Yeşil insan kaynakları eğitimleri vermek, iv) Yeşil uygulamaları kontrol etmek ve değerlendirmek ve v) Çevre performansıyla bağlantılı ödül sistemleri geliştirmek gibi (Tariq, Jan \& Ahmad, 2016).

Yeşil politikaları benimseyen işletmelerde insan kaynaklarının kilit görevi, mevcut sistem içerisinde ihtiyaç duyulan çevresel politikaların uygulanmasına yönelik olarak çalışanlara ve yöneticilere rehberlik etmektir (Supriya, 2017). İş stratejisi ve İKY uygulamaları arasındaki tutarlılığın örgütlerin başarısında önemli bir bileşen olduğu kabul edildiğinde, insan kaynaklarının stratejik ortak olabilmesi için, İK yöneticilerinin stratejik karar verme süreçlerinde diğer üst düzey yöneticilerin yanında yer alması gerekmekte ve İK hedefleri, stratejileri, felsefesi ve uygulamaları ile kurumsal hedefler uyumlu hale getirilmedir. Söz konusu uyumun sağlanabilmesi ve işletmenin yeşil uygulamalara geçişinin desteklenmesine yönelik olarak gerçekleştirilebilecek yeşil insan kaynakları yönetimi fonksiyonları aşağıda ele alınmıştır.

\subsection{Yeșil İșe Alım}

Yetenekli ve bilinçli insan kaynağının işe alınması insan kaynaklarının kilit alanlarının başında gelir.
Günümüzde birçok işletme ve özellikle de çok uluslu işverenler, Yeşil İKY uygulamalarını, adaylar üzerinde çekicilik oluşturmaya yönelik işveren markası çalışmaları olarak görmektedir. Yeşil İKY uygulamalarını benimsemek işletmelere daha geniş ve yüksek kaliteli bir aday havuzu sunmaktadır. Çok uluslu şirketler, yeşil uygulamalar ve sürdürülebilirlik konularında bilgi birikimi ve anlayışa sahip, son derece vasıflı ve yetenekli çalışanları cezbetmek için Yeşil İKY uygulamalarına özellikle önem vermektedir. Diğer taraftan iş arayanlar da işletme değerlerini kendilerine yakın hissettikleri, çevresel itibarı ve imaj1 yüksek olan şirketleri tercih etme eğilimindedirler. Kendilerini uluslararası yeşil kültürün standartlarına göre hazırlamakta ve yeşil çalışanlar olmak için gerekli becerilere sahip olmaya çalışmaktadırlar (Bhutto \& Auranzeb, 2016). Son dönem konuya yönelik yapılan birçok araştırma yüksek başarı sağlayan mezunların, iş başvurusu için karar alırken işletmenin çevresel performansını ve itibarını göz önüne aldığını ortaya koymaktadır. Benzer şekilde, iş arayanların yeşil kimlik bilgileri olan şirketlere daha yüksek ilgi duydukları tespit edilmiştir (Zibarras \& Coan, 2015).

Yeşil işe alım, çevre üzerinde en az etkiye sahip, kağıtsız işe alım süreci anlamına gelir. Süreç içindeki en önemli odak noktasının çevre olduğu bir sistemdir. İnsan kaynakları yönetiminin ve sürdürülebilirliğin en önemli faydaları, kalıcılık ve memnuniyettir (Holtom, Mitchell, Lee \& Eberly, 2008). İşletmeler günümüzde yeşil işveren olarak itibar kazanmanın yeni yetenekleri çekmenin etkili bir yolu olduğunu fark etmeye başlamıştır. Yeşil işe alım uygulamaları, yeni istihdamların organizasyonun çevre kültürüne aşina olmasını ve çevresel değerlerini benimsediğini garantileyerek etkili çevre yönetimini de destekleyebilir (Wehrmeyer, 1996).

Çevreye duyarlı bir şekilde iş arama ve bulma konusunda başvuru sahiplerinin etkili şekilde bilgi almaları önem taşır. Örneğin işverenlerin, işe alım süreçlerinde web tabanlı sistemleri tercih etmeleri, geleneksel yöntemlere göre kurumlar hakkında daha geniş bilgi sunmalarına olanak sağlamaktadır (Renwick, Redman \& Maguire, 2013). Kurumun çevresel politikaları ve uygulamalarının kendi web siteleri üzerinden yayınlanması, iş arayan adayların başvuru sürecinden önce bu bilgilere ulaşabilmesi önemlidir. İşletmenin işe alım sürecinden itibaren yeşil uygulamaları benimsemesi nitelikli başvuruları çekmesine yardımcı olacaktır (Guerci, Montanari, Scapolan \& Epifania, 2016).

Bilim ve teknoloji alanındaki yenilikler ile birlikte iletişimin hızı ve biçimi de değişmiştir. İnsan 
kaynakları yönetimi çevresel bozulma oranını azaltmaya yönelik olarak online başvuru formu, online röportajlar, video konferans, telekonferans veya telefon görüşmeleri gibi dijital yöntemlerle yapılan görüşmelerle kâğıt atıklarının azaltılmasını desteklemekte ve aynı zamanda görüşme ile ilgili yakıt tüketiminin de azalmasını sağlamaktadır. Söz konusu yeşil uygulamalar şirketlerin maliyetlerini düşürmesinde de bir etken olmaktadır (Khurshidi \& Darzi, 2016).

\subsection{Yeşil Performans Yönetimi}

İnsan kaynaklarında performans yönetimi, organizasyona sürdürülebilir rekabet avantajı sağlamak için, bireylerin ve ekiplerin yeteneklerini geliştirmenin bir prosedürüdür. Örgütlerin farklılaşmak ve rekabet avantajı yaratmada en önemli faktörü çalışanlarıdır. Buradan yola çıkarak örgütlerin çalışanların yetkinliklerini işletme hedefleriyle ilişkilendirmek için performans sistemi büyük önem taşır. Yöneticiler, çalışanlarının yeşil uygulamaları benimsemelerini, yeşil fikirler sunmalarını bu sistemler ile sağlayabilirler. Performans değerlendirmesinde yeşil süreçlerin kullanımı önemli performans alanlarından biri olmalıdır. Yeşil performans değerlendirmesi çalışanların yeşil süreçlere dahil olmasını da teşvik eder.

Performans değerlendirmesi belirli yeşil hedefler ve görevlerle bağlı olabilir. Çevresel olaylar, çevresel sosyal sorumluluk alanları da sürece dahil edilerek sistem kurulabilir. Örneğin Tata Şirketler Grubu, çevresel performans standartlarını ölçmek, yeşil bilgi sistemleri ve denetimlerini gerçekleştirmek için, çevresel performans standartlarını (yerinde kullanım, atık yönetimi, çevresel denetimler ve atıkların azaltılması gibi) geliştirmiştir. Başka bir örnekte Hindistan'daki ITC firmasıdır. Söz konusu işletme dünyadaki karbon, su ve atık geri dönüşümü pozitif olan tek şirket olma yönünde çalışmalar yapmış ve hedefine ulaşmıştır. Bu gibi standartlar üst yönetimin konuyla ilgili ciddiyetini ortaya koymakta ve çalışanları motive etmektedir (Sengupta \& Sengupta, 2015).

Performans yönetimi, yeşil uygulamaları arttırmada çalışanların motivasyon ve tutumlarını yükseltmeye yönelik önemli bir süreçtir. İşletmelerin yeşil performans yönetimi sistemleri geliştirmeleri için atabileceği adımlar aşağıda özetlenmiştir;

- İşletmenin performans sistemine dahil edilebilmesi için ölçülebilen bir dizi performans göstergesi geliştirmek,

- İşletmenin çevresel hedefleri ve yeşil girişimlerinin tüm çalışanlarla açıkça paylaşılmasını sağlamak,
- İşletme yöneticilerinin yeşil sonuçlarla ilgili beklentilerini açıkça belirtmek,

- Kilit performans göstergelerini açıkça tanımlamak,

- Yeşil hedeflere ulaşan çalışanları ödüllendirmek (Dumont, 2015).

\subsection{Yeşil Eğitim ve Geliştirme}

Şirketlerin rekabete ayak uydurabilmesi ve ayakta kalabilmesi, değişen şartlara ve koşullara uyum sağlaması ile gerçekleşmektedir. $\mathrm{Bu}$ noktada çalışanlarını bu değișime yönlendirmeleri de eğitim ve gelişim yoluyla mümkün olmaktadır. Eğitim ve geliştirme çalışanların belirli konulardaki yetkinliklerini arttırma, değişime ayak uydurabilme kapasitelerini geliștirme gibi rekabet alanında işletmeyi bir adım ileriye taşıyacak çok önemli bir yere sahiptir. İşletmeler yeşil eğitim stratejileri ile çalışanlarını çevresel bozulma nedenleri, enerjilerin ve kaynakların doğru kullanımı konularında bilinçlendirmelidir.

Çevresel eğitimler iki amaca hizmet etmektedir. Birincisi, çalışanlara işletmenin çevre politikasını öğretmek, ikincisi ise çalışanların çevre ile daha bilinçli ve kalıcı bir ilişki kurması için bireysel davranışlarını geliştirmektir. $\mathrm{Bu}$ iki amaç özellikle gelişmekte olan endüstriyel sektörler ve hizmet sistemleri için son derece önemlidir. Yeşil eğitim ve geliştirme sistemi aşağıdaki süreç yardımıyla hayata geçirilebilir:

1. Eğitim ihtiyaçlarının tanımlanması: Şirket genelinde gerekli yetkinliklerin oluşturulmasına yönelik eğitim açığının tespit edilmesi.

2. Eğitim tasarımı ve planlaması: Çevre eğitiminin niteliği, rolleri ve sorumluluklarının belirlenmesi, eğitim programının oluşturulması ve tüm organizasyon çalışanlarına sunulması. Özellikle bu aşamada eğitimlerin zaman ve kaynak tasarrufu sağlanacak şekilde tasarlanması önem kazanır (kâğıt kullanımının azaltılması, elektronik ortamların kullanılması vb.)

3. Eğitimin yürütülmesi: Eğitim altyapısı ile ilgili kararların verilmesi ve planlanan şekilde yetkililer tarafindan sürdürülmesi.

4. Eğitim sonuçlarının değerlendirilmesi: Sunulan eğitimin ve eğitimli kişilerin memnuniyetinin kaydedilmesi (Teixeira, Jabbour \& Jabbour, 2012).

Yeşil Eğitim ve gelişim programlarına, şirketin her seviyesinde görev alan çalışanlar katılmalı, eğitim 
içerikleri sosyal ve çevresel tüm konulardaki bileşenleri kapsamalıdır. Eğitim programları yeni işe alınan çalışanların oryantasyon programlarının, yeşil bilinçlendirme, yeşil prosedür ve süreçler hakkında bilgilendirilmesi ile başlamalıdır. Hatta şirket içerisinde her bölümde yeşil ekipler oluşturularak devamlılığı sağlanmalıdır (Ahuja, 2015).

Eğitmen sunumlarını video ve konferans yöntemiyle vermelidir. Eğitmen kâğıt kullanımı azaltmak için basılı materyaller yerine, online ortamdan içerikler ile eğitimi planlamalıdır (Nayak \& Mohanty, 2017).

Kurumların karşılaştığı önemli bir zorluk, verimli aynı zamanda teşvik edici bir eğitim sunmaktır. Bu eğitimler, işyerinin yeşil analizi, organizasyon içindeki potansiyel yeşil yöneticiler için iş rotasyonları, çevresel yönetim eğitimleri ve programları, geri dönüşüm, atık yönetimi, enerji verimliliği ve güvenliği eğitimleri ve şirketin çevresel uygulamalarını kapsamalıdır. İK etkileşimli öğrenme teknikleri kullanarak ve çalışanların kendi örgüt tabanlı materyallerini geliştirmeye teşvik ederek yeşil eğitime olan katılımları desteklenmelidir (Renwick, Redman \& Maguire, 2013). Yeşil eğitimler uygulandıktan sonra, çalışanlar edinmiş oldukları bilgileri işlerine, çalışma hedeflerine ve eylem planlarına nasıl uygulayabilecekleri konusunda öneriler sunmaya teşvik edilmelidir (Milliman, 2013).

\subsection{Yeşil Ücretlendirme ve Yan Haklar}

Yeşil ücretlendirme ve yan haklar Yeşil İKY'nin bir diğer önemli fonksiyonudur. İşletmelerin çevresel performansının sürdürülebilirliği de bu konu ile yakından ilişkilidir. Aynı zamanda bu süreç, çalışanları motive etmek için de son derece önemlidir. Bazı şirketler konuyu maddi boyutuyla uygularken, bazıları da manevi olarak uygulayabilmektedirler (Opatha \& Arulrajah, 2014). Çalışanlara değişen davranışları için bir ödül sistemi hayata geçirilerek, sürdürülebilir girişimlerin kazanılması yan haklar sürecine dahil edilmelidir. $\mathrm{Bu}$ yan haklar eko-performansa bağlanarak ücret paketine de eklenebilmektedir (Supriya, 2017).

Yeşil ücretlendirme ve yan haklar, çevresel hedeflerin gerçekleştirilmesi için çalışanları teşvik etmeye yardımcı olabilecek çevresel faaliyetlerin desteklenmesi için güçlü bir araçtır ve aşağıda özetlendiği gibi birçok şekilde olabilir;

- Yeşil becerilerin kazanılmasını desteklemek için ödül paketleri tasarlamak

- Maddi temelli ödüller (ikramiye, prim vb.)
- Manevi temelli ödüller (özel tatil izni, hediye, akşam yemeği promosyonlar vb.)

- Olumlu geri bildirimler (Bangwal \& Tiwari, 2015)

- Tanınmaya yönelik ödüller (yılın yeşil çalışanı, takdir etmek için ödül törenleri vb.) (Khurshidi \& Darzi, 2016)

Organizasyonlar, teşvikler ve çeşitli caydırıcı önlemler içeren ödül sistemleri geliştirerek arzu edilen yeşil davranışların üretilmesini sağlayabilirler. Çalışanlara, yeşil davranışların bilincinde olmalarını teşvik eden e-posta veya yöneticilerden alınan sözlü değerlendirmeler gibi teşvikler yardımıyla olumlu geribildirimler sunulabilir. Buna ek olarak yeşil davranışlarda aksaklıktan kaçınmaya yönelik olarak ihtar, eleştiri veya askıya alma gibi engelleyici yöntemlere de başvurulabilmektedir (Mehta \& Chugan, 2015).

\subsection{Yeşil Çalışan İlişkileri}

İyi çalışan ilişkileri kurmak insan kaynakları yönetiminin önemli unsurlardan biridir. Bu sayede, bireysel çalışanların motivasyonu artacak ve moralleri yükselecek, dolayısıyla işletmenin verimliliği pozitif yönde etkilenecektir. Yeşil çalışan ilişkileri de organizasyonlar için bir avantaj ve iyileştirme kaynağıdır.

Yeşil süreçlerde çalışanın katılımı, bireysel amaçlarını, motivasyonlarını ve algılamalarını yeşil yönetim uygulamaları ve sistemleri ile uyumlu hale getirdiği için başarılı bir yeşil yönetim uygulaması sağlar. Çalışan ilişkilerinin kapsamı, üst düzey yönetimden alt kademeye kadar her çalışanın süreçlere dahil olduğu ve fikir paylaşımında bulunabileceği bir süreç olarak tasarlanmalıdır (Deepika \& Karpagam, 2016).

Paylaşılan bir vizyon, işletmelerin geleceği için örgütün ortak hedeflerini ve isteklerini ifade edebilir. Dahası, paylaşılan bir vizyon bütüncül hedeflerden oluşan stratejik bir yön verir. Çalışanların faaliyetlerini daha derin ve daha büyük bir bağlamda görmelerini sağlayabilir. Aynı zamanda bir ortaklık duygusu oluşturmaya ve işletmenin farklı faaliyetlerinde bir tutarlılık sağlamaya yardımcı olur. Ortak bir vizyon, şirketin karşılıklı hedefler belirleyerek, standartları netleştirerek ve ortak bir çalışma geliştirerek, çalışanların kendilerini etkin bir şekilde yönetmelerini sağlayabilir. Entegre, net ve paylaşılabilir bir vizyon tanımlamak ve iletişsim kurmak, rekabet avantajı elde etmek için atılan ilk adımdır. Paylaşılan bir vizyon, insan kaynağının örgütsel amaçlar doğrultusunda daha yüksek üretkenliğe sahip ve motive bir şekilde çalışmasını sağlayarak stratejik amaçların gerçekleştirilmesini 
desteklemektedir (Chen, Chang, Yeh \& Cheng, 2015). Dolayısıyla yeşil çalışan ilişkilerini kurmanın ilk adımı karar verme süreçlerine insan kaynağının dahil edilmesinden geçer.

Çalışanların karar verme süreçlerine katılım sağlayabilecekleri ortamın oluşturulması, onları yeşil süreçlere hazırlayacaktır. Çalışan ilişkilerinin koordinasyonunun sağlanması ve geliştirilmesi yoluyla süreçlerin iyileştirilmesine katkıda bulunulacaktır. Çalışanları karar süreçlerine dahil etmek, onları ekolojik çalışmalarda yer almaları konusunda motive edecektir. Ayrıca çalışanlara sorumluluk vermek, örgütün yeşil uygulamalara geçiş sürecinde katılımcı bir ortam yaratacaktır. $\mathrm{Bu}$ değişim sürecinde sürekli geri bildirimde bulunulması da daha iyi sonuçlar alınmasını sağlayacaktır (Stojanoska, 2016).

Buna ek olarak işyerindeki bireysel ve gönüllü vatandaşlık girişimleri, yeşil uygulamalarının organizasyonlar içindeki etkinliğini artırmada önemli rol oynayabilir. Koruyucu önlemlerin geliştirilmesiyle birlikte, işyerinde katılımeı ve gönüllü davranışlar kirliliğin azaltılmasında vazgeçilmez bir unsur haline gelmiştir. Örgütsel vatandaşlık davranışları yalnızca işletmeleri ve çalışanları değil, genel olarak toplumu ve ekosistemlerin korunmasını sağlayarak çevresel kaygılar doğrultusunda yönlendirilebilir. Örgütsel faaliyetlerin çevresel etkisi, çok sayıda sosyo-teknik faaliyetin ve davranışların kombinasyonunu içerir. Örneğin, bir organizasyonda geri kazanılan ve geri dönüştürülmüş kalıntıların hacmi, işyerindeki birçok kişinin davranışına bağlıdır. Çalışanlar, iş süreçlerindeki proseslere yakınlıkları nedeniyle de, düzensizlikleri tespit etmek veya kirletici emisyon kaynaklarını bulmak için en iyi konumdadır. Örneğin üretim işletmelerinde operatör konumundaki çalışanlar sıklıkla süreçlerden kaynaklanan toksik ürünlerin kronik sızıntılarını gözlemleyebilir veya önemli çevresel etkilere neden olabilecek teknik arızları belirleyebilir. $\mathrm{Bu}$ tür çevresel konuların tespiti, çalışanların paylaşmayı seçebilecekleri veya paylaşmayacakları gizli bilgiyle ilgilidir. İşte bu noktada, bireysel ve isteğe bağlı örtük bilginin paylaşımı, kirliliği önlemeye yönelik önlemlerin geliştirilmesi için gerekli olan örgütsel vatandaşlık davranışlarına bağlıdır. Çevresel örgütsel vatandaşlık davranışları, ekolojik çözümler aranması ve önleyici tedbirlerin uygulanmasında yardım ve iş birliğinin teşvik edilmesi için önemlidir. Genel olarak çevresel örgütsel vatandaşlık davranışları kirlilik önlemede etkinliğin geliştirilmesine katkıda bulunmakta ve ekolojik konuların günlük faaliyetlere entegrasyonunu teşvik eden bir sosyal bağlam yaratmaya yardımcı olmaktadır (Boiral, 2009).

\subsection{Yeşil İş-Yaşam Dengesi}

Yeşil iş-yaşam dengesi, sürdürülebilir değer yaratmak için kurumların kurumsal hedeflerine ve kültürüne dahil edilmesi gereken potansiyel bir stratejik insan kaynakları aracıdır. Yeşil işyeri politikaları, iş dünyasının ve yaşamın olumlu etkileşimlerini teşvik ederek, yönlendirir. Bazen çalışanlar, işyerinde çevre dostu uygulamaları benimserken, kişisel hayatlarında bu durumu görmezden gelmeye devam edebilmektedirler. $\mathrm{Bu}$ da bir dengesizlik yaratmakta ve aslında organizasyonun yeşil hedeflerine tamamen ulaşılmasını engellemektedir. $\mathrm{Bu}$ nedenle işletmeler, Yeşil İKY'nin hedeflerine tamamen ulaşılmasını sağlamak için her iki alanda da yeşil değerlerin benimsenmesini teşvik etmelidir.

Yeşil İKY süreçlerinde yalnızca çalışanların mesleki rolü üzerine odaklanılır ve çalışma dışı roller göz ardı edilirse, Yeşil İKY'nin tam potansiyeli gerçekleşmez. İşyeri, çalışanın hayatında önemli iki alandan biridir. Yeşil kişiliğin ve çalışanların yeşil tutumlarının büyük payı çalıştığı işletme tarafından şekillendirilir (Datta, 2015).

Yeşil davranışlar, insanların yaşam tarzlarının bir parçası haline gelen tüketim kalıplarını da etkilemektedir. Yeşil IKKY uygulamaları, çalışanların doğal kaynakların işletilmesinden haberdar edilmelerini ve çevre dostu ürünler için destek geliştirmelerini sağlar. Kişilerin özel hayatları ve iş hayatları arasında bir bağlantı olduğundan çalışanların örgütlerde geliştirdikleri davranışlar özel yaşamlarını da etkilemektedir. Bu sebeple işyerindeki yeşil uygulamalardan çalışanların özel yaşamlarına kadar bir yayılma etkisi söz konusudur (Ragas, Tantay, Chua \& Marie, 2017). Başka bir deyişle, Yeşil İKY'nin tam potansiyelini ortaya koyabilmek için insan kaynaklarını hem üretici hem de tüketici konumunda düşünmek gerekmektedir. Bu anlamda çalışanların sadece işle ilgili yeşil İK politikaları izlemesi yetersiz kalacaktır. Özel yaşam ve çalışma hayatında çevre dostu davranışların karşılıklı olarak uygulanması bir denge sağlayacaktır (Muster \& Schrader, 2011).

\section{SONUÇ}

Öncelikle, işletmelerin çevresel performansı, küresel ticaret gündeminde ortaya çıkan bir konudur ve etkin çevresel yönetim, dünyanın farklı bölgelerindeki birçok işletme için büyük bir öncelik haline gelmiştir. Günümüz işletmeleri için çevresel 
performans, daha yüksek karlılık ve daha iyi finansal çıktılar gibi olumlu sonuçlara yol açar.

Buna ek olarak küreselleşme ile birlikte artan çevre sorunları toplumu bu konuda daha bilinçli olmaya yönlendirmiştir. Tüketiciler, çevre dostu üretim ve süreçleri benimseyen firmaları seçme eğilimindedir. Toplumun bilinçli davranması, firmaları da bu konuda çalışmalar yapmaya sevk etmiştir. İşletmelerin, bugünün iş dünyasında rekabet edebilmesi konusunda yeşil ekonomi önemli bir rekabet unsuru haline gelmiştir. Yapılan araştırmalarda yeşil yönetimi benimseyen işletmelerin hem tüketici hem de potansiyel çalışanlar için tercih edilme olasılıklarının yüksek olduğu konusunda bulgular ortaya çıkmıştır.

Yeşil yönetimi benimseyen kuruluşların, insan kaynakları süreçleri ile çevre dostu uygulamalarını entegre etmesi gerekmektedir. Yeşil İKY, kurumların müşterileri, çalışanları ve tedarikçileri ile güçlü bir iletişim kurmasına yardımcı olabilir. Aynı zamanda çevreye duyarlı şirketlerin, gerçekleştirdiği uygulamalar da kurum imajına olumlu bir katkı sağlayacaktır. Bu olumlu imaj, çalışanları ve müşterileri kuruma çekmekte önemli bir güç olarak görülebilir. Yeşil süreçleri benimseyen şirketlerin, öncelikle bu bilinci kurumlarının vizyon, misyon ve stratejileri ile de uyumlu hale getirmesi gerekir.

Kurumların hedef ve stratejilerinin geliştirilmesinde insan kaynakları profesyonelleri, iş ortağı olarak önemli bir rol üstlenmektedir. İnsan kaynakları yönetiminin, şirketlerinin İK politikalarını yeşil süreçlere göre yapılandırması, başta işe alım olmak üzere, eğitim, geliştirme, performans yönetimi, ücretlendirme, çalışan ilişkileri ve iş-yaşam dengesi alanlarında uygulanabilir hale getirmesi gerekmektedir. Yeşil bir işletme oluşturmak için İK'nın daha motive, çevresel süreçlere uyum sağlayacak ve benimseyecek çalışanları işe alma ve bu çalışanlarda aidiyet duygusu oluşturmaları önem arz etmektedir. Bu konuda motive edilmiş çalışanlar şirketlerin hedefleri ve başarısında büyük katkı sağlayacaktır. İK profesyonelleri, yeşil yönetim hedeflerini belirleyerek ve bunları tüm şirket kademelerinde etkin bir şekilde paylaşmak ve uygulamak suretiyle etkin bir Yeşil İKY benimsenmesini sağlayabilirler.

İnsan kaynakları yöneticileri, insan kaynakları politikaları ile kurumsal misyonda belirtilen yeşil insan kaynakları felsefesini birleştirmenin ek sorumluluğu ile görevlendirilmiştir. Yeşil insan kaynakları çalışmaları, artan verimlilik, maliyet düşüşü, çalışanların elde tutulması ve daha fazla üretkenlik gibi birçok somut faydalarla sonuçlanmaktadır. Bu sebeple insan kaynakları, belirlenen yeşil yönetim politika ve stratejilerine uygun İK uygulamalarını hayata geçirmelidirler. Yeşil İKY, kurumlara rekabet avantajı sağlayacak, çevre konularında bilinçli adayları işletmeye kazandıracak işe alım politikaları oluşturmalıdır. İşe alınan çalışanların oryantasyon süreçlerinden başlayarak, çevresel yönetim uygulamaları, bilinçlendirme eğitimleri, atık yönetimi, enerji tasarrufu vb. konularda eğitim planlamaları tasarlayıp hayata geçirmek İK'nın önemli faaliyetlerinin başında yer alır. Performans yönetimi süreçlerinde de işletme tarafından belirlenen çevresel hedeflerin çalışanlar ile paylaşılması, onları teşvik etme konusunda faydalı olacaktır. Çalışanların, şirket hedeflerini benimsemesi ve yeşil faaliyetler ile ilgili öneriler sunmalarını desteklemek amacıyla ödüllendirme programlarının uygulanması da motivasyon artırma ve süreçleri içselleştirme konusunda faydalı olacaktır.

Günümüz iş dünyasında işletmeler için en önemli rekabet unsurlarından biri şüphesiz çalışanlarıdır. $\mathrm{Bu}$ nedenle yöneticiler, çalışanları teşvik etmek, uzun vadeli iş ilişkileri kurmak konusunda yoğun çaba göstermektedir. $\mathrm{Bu}$ noktada da insan kaynaklarının önemi bir kez daha ortaya çıkmaktadır. Yeşil İKY süreçlerinde, İK profesyonellerinin tüm işletme düzeyinde benimsenen ortak bir değer yaratma rolü önem arz etmektedir. 


\section{KAYNAKÇA}

Ahuja, D. (2015). Green HRM: Management of people through commitment towards environmental sustainability, International Journal of Research in Finance and Marketing, 5(7), 50-54.

Ashraf, F., Ashraf, I. \& Anam, W. (2015). Green HR for businesses. International Journal of Academic Research in Business and Social Sciences, 5(8), 149156.

Bangwal, D. \& Tiwari, P. (2015). Green HRM - A way to greening the environment. Journal of Business and Management, 17(12), 45-53.

Bhutto, S. A. \& Auranzeb (2016). Effects of green human resources management on firm performance: An empirical study on Pakistani firms. European Journal of Business and Management, 8(16), 119-125.

Boiral, O. (2009). Greening the corporation through organizational citizenship behaviors. Journal of Business Ethics, 87(2), 221-236.

Chen, Y., Chang, C., Yeh, S. \& Cheng, H. (2015). Green shared vision and green creativity: The mediation roles of green mindfulness and green self-efficacy. Quality \& Quantity, 49(3), 1169-1184.

Cherian, J. \& Jacob, J. (2012). A study of green HR practices and its effective implementation in the organization: A review. International Journal of Business and Management, 7(21), 25-33.

Clark, R. S. (2013). The importance of human resource managements' strategic role in organizational sustainability (Unpublished doctoral dissertation). Capella University, Minnesota, USA.

Datta, A. (2015). Green work-life balance: A new concept in green HRM, International Journal of Multidisciplinary Approach and Studies, 2(2), 83-89.

Deepika, R. \& Karpagam, V. (2016). A study on green HRM practices in an organisation. International Journal of Applied Research, 2(8), 426-429.

Dilchhert, S. \& Ones, D.S. 2012. Environmental sustainability in and of organizations. Industrial and Organizational Psychology, 5, 503-511.

Dumont, J. (2015). Green human resource management and employee workplace outcomes (Unpublished doctoral dissertation). University of South Australia, Australia.

Dumont, J., Shen, J. \& Deng, X. (2017). Effects of green hrm practies on employee workplace green behavior: The role of psychological green climate and employee green values. Human Resource Management, 56(4), 613-627.
Guerci, M., Montanari, F., Scapolan, A. \& Epifania, A. (2016). Green and nongreen recruitment practices for attracting job applicants: Exploring independent and interactive effects. The International Journal of Human Resource Management, 27(2), 129-150.

Harris, C. \& Tregidga, H. (2012). HR managers and environmental sustainability: Strategic leaders or passive observers? The International Journal of Human Resource Management, 23(2), 236-254.

Ho, Y., Lin, C. \& Tsai, J. (2014). An empirical study on organizational infusion of green practices in Chinese logistics companies. Journal of Economic and Social Studies, 4(2), 159-189.

Holtom, B.C., Mitchell, T.R., Lee, T.W. \& Eberly, M.B. (2008). Turnover and retention research: A glance at the past, a closer review of the present, and a venture into the future. The Academy of Management Annals, 2, 231-274.

Jong, J. Y. \& Yusoff, Y. M. (2016). Studying the influence of strategic human resource competencies on the adoption of green human resource management practices. Industrial and Commercial Training, 48(8), 416-422.

Khurshidi, R. \& Darzi, M. A. (2016). Go green with green human resource management practices. International Journal of Research in Commerce \& Management, 7(1), 19-21.

Kramar, R. (2014). Beyond strategic human resource management: Is sustainable human resource management the next approach? The International Journal of Human Resource Management, 25(8), 1069-1089.

Lakshmi, V. \& Kennedy, H. (2017). The role of business sustainability in human resource management: A study on Indian manufacturing companies. The South East Asian Journal of Management, 11(1), 70-85.

Mehta, K. \& Chugan, P. K. (2015). Green HRM in pursuit of environmentally sustainable business, Universal Journal of Industrial and Business Management, 3(3), 74-81.

Millar, J. H., Sanyal, C. \& Camen, M. M. (2016). Green human resource management: A comparative qualitative case study of a United States multinational corporation. The International Journal of Human Resource Management, 27(2), 192-211.

Milliman, J. (2013). Leading-edge green human resource practices: Vital components to advancing environmental sustainability. Environmental Quality Management, 23(2): 31-45.

Muster, V. \& Schrader, U. (2011). Green work-life balance: A new perspective for green HRM. German 
Journal of Human Resource Management, 25(2), 140-156.

Nayak, S. \& Mohanty, V. (2017). Green HRM for business sustainability. Indian Journal of Scientific Research, 15(2), 102-105.

O’Donohue W. \& Torugsa, N. (2016). The moderating effect of 'Green' HRM on the association between proactive environmental management and financial performance in small firms. The International Journal of Human Resource Management, 27(2): 239-261.

Opatha, H. H. D. N. P. \& Arulrajah, A. A. (2014). Green human resource management: Simplified general reflections. International Business Research, 7(8), 101-112.

Pandey, S., Viswanathan, V. \& Kamboj, P. (2016). Sustainable green HRM - Importance and factors affecting successful implementation in organizations. International Journal of Research in Management and Business, 2(3), 11-29.

Ragas, S. F. P., Tantay, F. M. A., Chua, L. J. C. \& Marie, C.S. (2017). Green lifestyle moderates GHRM's impact on job performance. International Journal of Productivity and Performance Management, 66(7), 857-872.

Raikkönen, T. (2011). The greening of work: How green is green enough? Nordic Journal of Working Life Studies, 1(1), 117-133.

Renwick, D. W. S., Redman, T. \& Maguire, S. (2013). Green human resource management: A review and research agenda. International Journal of Management Reviews, 15(1), 1-14.

Sengupta, M. \& Sengupta, N. (2015). Green HRM: A tool for organizational sustainability. Presented at_the Fourth International Conference on Global Business, Economics, Finance and Social Sciences Conference, Kolkata-India.

Stojanoska, A. (2016). Green human resource management: The case of gorenje group (Unpublished master dissertation). University of Ljubljana, Slovenya.

Supriya, G. K. (2017). Environmental sustainability with special refference to green HRM. International Journal of Advanced Research in Engineering \& Management, 3(9), 41-44.

Tariq, S., Jan, F. A. \& Ahmad, M. S. (2016). Green employee empowerment: A systematic literature review on state-of-art in green human resource management. Quality \& Quantity, 50(1), 237-269.

Teixeira, A. A., Jabbour, C. J. C. \& Jabbour, A.B.L.S. (2012). Relationship between green management and environmental training in companies located in
Brazil: A theoretical framework and case studies. International Journal of Production Economics, 140(1), 318-329.

Wehrmeyer, W. (1996). Greening people - Human resources and environmental management, Sheffield, England: Greenleaf Publishing.

Zibarras, L. D. \& Coan, P. (2015). HRM practices used to promote pro-environmental behavior: A UK survey. The International Journal of Human Resource Management, 26(16), 2121-2142. 